\title{
Breast cancer and oral contraceptives: findings in Royal College of General Practitioners' study
}

\author{
ROYAL COLLEGE OF GENERAL PRACTITIONERS
}

\begin{abstract}
The incidence of breast cancer was studied among women taking part in the continuing cohort study organised by the Royal College of General Practitioners. An overall relative risk of $1 \cdot 19$ (not significant) was found in those who had used oral contraceptives. The risk ratio in women under 35 years old was 2.81 , but this too was not significant. There was evidence that the estimated increased risk for younger women could be a chance occurrence.

No convincing evidence of any adverse effects of oral contraceptives on breast cancer has been shown, but because of the long latent period of this tumour there is a need for longer observation.
\end{abstract}

\section{Introduction}

The possible association of oral contraceptives with an increased incidence of breast cancer has been a major concern. The tumour is hormonally dependent and is common enough for even a small increased relative risk in users of oral contraceptives to constitute an important personal and public health hazard. This paper presents the relevant data up to December 1979 from the large-scale cohort study organised by the Royal College of General Practitioners (RCGP).

\section{Methods}

The organisation of the study, the potential biases in the data, and the principles underlying the interpretation of the results have all been described in detail elsewhere. ${ }^{1}$ In summary, 23000 women using oral contraceptives and a similar number of controls who had never used oral contraceptives were entered by 1400 general practitioners in Britain over 14 months from May 1968 for continuing observation.

This report was prepared by Dr Clifford Kay, director of the RCGP Manchester Research Unit Oral Contraceptive Study.
The users and their controls were matched for age, and all subjects were married or living as married. Information about oral-contraceptive use, the diagnosis of all newly presenting episodes of illness, and other relevant data were collected for each subject every six months from her date of recruitment to the study. Each calendar month in which a subject used an oral contraceptive contributed to the period of exposure of current users. When a user stopped taking the pill her subsequent period of observation was included in the group of former users until she resumed oral contraceptives, after which her experience was again attributed to the current-user group. Controls were women who had never used oral contraceptives. If they started using oral contraceptives they were included in the current-user group from the time of the change. For some analyses it was appropriate to combine the experience of current users with that of former users and to study all those who had ever used oral contraceptives.

The analyses were based on the first report of a diagnosis of breast cancer in any woman after recruitment to the study. In each group event rates were calculated in the computer using the cumulative relevant woman-months of observation as the denominator, but they are presented here as rates per 1000 women-years. Unless stated otherwise, the rates in each group were standardised by the indirect method for age and parity at the time of diagnosis and for daily cigarette consumption and social class as determined at recruitment to the study. The experience of the total study population was used as the standard. Statistical tests for differences between the groups were calculated using the method described by Peto, ${ }^{1}$ and $95 \%$ confidence limits were determined by Miettinen's method. ${ }^{2}$

Since pregnancy modifies the occurrence and the reporting of many diseases, and the pregnancy rate was lower in those who have ever used contraceptives than in the controls, all events reported during pregnancy were excluded, together with the associated womanmonths of observation. In this respect these present analyses were consistent with our previous analyses of morbidity. There was, however, no important change in the present results when pregnancy was included.

We wanted an independent assessment of the histology of the reported breast cancers. All data for the study were collected in strict confidence, and the organisers never knew the names of the study subjects. To avoid breaking this important principle we asked the relevant general practitioners to send direct to $\mathrm{Dr} W \mathrm{~W}$ W Inman of the Committee on Safety of Medicines the names of the affected patients. Whenever possible, Dr Inman kindly arranged to collect the appropriate biopsy specimens from the hospitals where the operations had been carried out. The specimens were examined by Professor A C Thackray without knowledge of the patients' contraceptive use. He classified and graded the tumours using the system described by Scarff and Torloni. ${ }^{3}$ 
At the same time the opportunity was taken to determine from the general practitioner the manner in which the breast lesion had been discovered and the age at which the patient had given birth to her first child. Age at the first birth is an important determinant of the subsequent risk of developing breast cancer. ${ }^{4}$ It would have been of interest to determine whether any differences in this variable between the contraceptive groups had contributed to any differences in the incidence of breast cancer. Unfortunately, the need for this information for the whole study population was not recognised at recruitment, and it was impracticable to collect it later. Since parity is closely correlated with the age at first birth, however, the effects of any differences in the age at first birth between the groups should have been controlled substantially by standardisation for parity.

\section{Results and comment}

Table I shows that the relative risks of breast cancer between current users and controls and former users and controls were 1.26 and 1.14 respectively. Neither ratio was statistically significant. Because the effects of factors which influence the incidence of breast cancer take many years to become apparent, it is more realistic to combine the experience of current users and former users, and to compare those who have ever used oral contraceptives with controls. The risk ratio for women of all ages was $1 \cdot 19$ (table II). The mortality rate for the 19 women with breast cancer who used oral contraceptives was $0 \cdot 11$ and for the 10 controls it was 0.08 , giving a mortality risk of $1.45(95 \%$ confidence limits $0 \cdot 6-3 \cdot 6)$; the deaths of women who were diagnosed before recruitment to the study have been excluded. The estimated

TABLE I-Standardised breast-cancer rates per 1000 women-years by oralcontraceptive use

\begin{tabular}{llllcc}
\hline & & Rate & $\begin{array}{c}\text { Period of } \\
\text { observation } \\
\text { (woman years) }\end{array}$ & $\begin{array}{c}\text { Risk ratios } v \text { controls } \\
(95 \% \text { confidence } \\
\text { limits })\end{array}$ \\
\hline Current users $(\mathrm{n}=36)$ & $\ldots$ & $\ldots$ & 0.50 & 98551 & $1 \cdot 26(0.7-2 \cdot 2)$ \\
Former users $(\mathrm{n}=39)$ & $\cdots$ & $\ldots$ & 0.45 & 78142 & $1.14(0.7-1 \cdot 9)$ \\
Controls $(\mathrm{n}=58)$ & $\cdots$ & $\cdots$ & 0.39 & 129593 & \\
\hline
\end{tabular}

TABLE II-Breast-cancer rates per 1000 woman-years by age at diagnosis and oral-contraceptive use standardised for parity at diagnosis and for smoking habit and social class at entry. Totals and subtotals were also standardised for age within age ranges

\begin{tabular}{|c|c|c|c|c|c|c|}
\hline \multirow{2}{*}{$\underset{\text { (years) }}{\mathrm{Age}}$} & \multicolumn{2}{|c|}{$\begin{array}{l}\text { Women who had ever } \\
\text { used contraceptives }\end{array}$} & \multicolumn{2}{|c|}{ Controls } & \multirow{2}{*}{$\begin{array}{l}\text { Risk } \\
\text { ratio }\end{array}$} & \multirow{2}{*}{$\begin{array}{l}95 \% \\
\text { confidence } \\
\text { limits }\end{array}$} \\
\hline & No & Rate & No & Rate & & \\
\hline $\begin{array}{l}15-19 \\
20-24 \\
25-29 \\
30-34 \\
\end{array}$ & $\begin{array}{r}0 \\
0 \\
5 \\
17 \\
\end{array}$ & $\begin{array}{l}0.00 \\
0.00 \\
0.12 \\
0.40\end{array}$ & $\begin{array}{l}0 \\
1 \\
1 \\
4\end{array}$ & $\begin{array}{l}0.00 \\
0.13 \\
0.05 \\
0.12\end{array}$ & $\begin{array}{l}0.00 \\
2 \cdot 44 \\
3 \cdot 33^{*}\end{array}$ & $\begin{array}{l}0 \cdot 0-13 \cdot 0 \\
0 \cdot 1-45 \cdot 0 \\
1 \cdot 2-9 \cdot 2\end{array}$ \\
\hline $15-34$ & 22 & 0.24 & 6 & 0.08 & $2 \cdot 81$ & $1 \cdot 0-8 \cdot 0$ \\
\hline $\begin{array}{l}35-39 \\
40-44 \\
\geqslant 45\end{array}$ & $\begin{array}{l}12 \\
16 \\
25\end{array}$ & $\begin{array}{l}0.38 \\
0.76 \\
1.76\end{array}$ & $\begin{array}{l}15 \\
18 \\
19\end{array}$ & $\begin{array}{l}0.44 \\
0.72 \\
1.05\end{array}$ & $\begin{array}{l}0.87 \\
1.05 \\
1.68\end{array}$ & $\begin{array}{l}0.5-1 \cdot 7 \\
0.7-1.7 \\
0.3-10 \cdot 4\end{array}$ \\
\hline$\geqslant 35$ & 53 & 0.73 & 52 & 0.74 & 0.99 & $0 \cdot 9-1 \cdot 1$ \\
\hline All ages & 75 & $0 \cdot 47$ & 58 & 0.39 & $1 \cdot 19$ & $0 \cdot 8-1 \cdot 7$ \\
\hline
\end{tabular}

$* \mathrm{p}<0.05$. small increased risks in those who had ever used oral contraceptives could easily have occurred by chance.

The survival of the women with breast cancer was also determined using the life-table method. ${ }^{5}$ The patterns were closely similar in those who had ever used oral contraceptives and controls, and the five-year survival rate was $62 \%$ for those who had ever used oral contraceptives and $70 \%$ for the controls. This small difference was not statistically significant and was, of course, consistent with the small overall excess mortality risk in those who had ever used oral contraceptives. Five years after diagnosis 18 of those who had ever used oral contraceptives and 10 controls were surviving and still under observation.

Examination of the relative risks in each five-year age group (table II) suggested an increased risk for young women who had used contraceptives. Indeed, in the 30 to 34 years category, the risk ratio of 3.33 reached borderline statistical significance. The data were then grouped to provide the maximum contrast between younger and older women. The selection of dividing lines when large groups are broken down into smaller ones is subjective, so that it is not possible to attach the normal interpretation to the results of tests of significance. Nevertheless, the relative risk in women aged under 35 years who had ever used oral contraceptives was $2 \cdot 81$ and the standard test applied to this group suggested a probability greater than 0.05 . In these circumstances this provided stronger than usual support for the conclusion that the estimated increased risk could have been a chance occurrence. In addition, when the data were regrouped into underand over-40-years categories, the relative risks were about 1.3 in each group.

Nevertheless, having raised the hypothesis that young women who have used oral contraceptives are at higher risk, we had to seek supporting evidence. In addition to the age analysis, comparisons of the incidence of breast cancer between women who had ever used oral contraceptives and controls were made by parity, social class, and cigarette consumption. In these analyses the rates were standardised for the three remaining major variables, so that the independent effect of each variable could be examined in turn. The results were unremarkable. No material effect of oestrogen or progestogen dose could be detected in current users. There was no evidence of a trend in rates related to length of oral-contraceptive use (table III) in younger or older women or in all ages combined, even when the control rates (nil users) were included in the calculations. In a similar analysis confined to current users there was no material change when the data were additionally standardised for brand usage. This, of course, is an alternative method of investigating the effects of dose.

Professor Thackray's findings are presented in table IV. Most of the invasive tumours were ductal carcinomas with no special features. There were too few of the special types, such as medullary carcinoma, for valid comparison, and the histological grades of malignancy have been made the basis of comparison in the table. Specimens were unavailable from $24 \%$ of those using oral contraceptives and $34 \%$ of controls. The necessary information was unobtainable from the general practitioner (usually because of death or retirement) for 10 women who had used oral contraceptives at some time and seven controls and, additionally, no response was obtained from the relevant hospital for eight ever users and 11 controls. There was no reason to suspect that these circumstances were related to the histology of the specimens and, therefore, we do not believe that the specimens received were a biased sample. The analysis showed a slightly higher proportion of cases of greater invasiveness (grade III) in those who had used oral contraceptives, but the differences were not statistically significant. No important differences were shown when women under and over 35 years of age were analysed separately. Because the cases reported to us had attended hospitals throughout Britain we could not review the patients' clinical records to establish the staging of the tumour at presentation.

TABLE III-Breast-cancer rates per 1000 woman-years by duration of oral-contraceptive use standardised for age and parity at diagnosis and for smoking habit at entry. Former users were excluded, and numbers of patients are shown in parentheses

\begin{tabular}{|c|c|c|c|c|c|c|c|c|c|c|}
\hline Years of use: & $\begin{array}{c}0 \\
\text { (controls) }\end{array}$ & 1 & 2 & 3 & 4 & 5 & 6 & 7 & 8 & $8+$ \\
\hline $\begin{array}{c}\text { Age (years): } \\
<35^{*} \\
\geqslant 35 \dagger \\
\text { All ages } \$\end{array}$ & $\begin{array}{l}0.09(6) \\
0.74(52) \\
0.39(58)\end{array}$ & $\begin{array}{l}0.22(2) \\
0.00(0) \\
0.28(2)\end{array}$ & $\begin{array}{l}0.21(2) \\
0.85(2) \\
0.51(4)\end{array}$ & $\begin{array}{l}0.22(2) \\
1.08(3) \\
0.59(5)\end{array}$ & $\begin{array}{l}0.12(1) \\
0.33(1) \\
0.23(2)\end{array}$ & $\begin{array}{l}0.99(7) \\
0.00(0) \\
0.83(7)\end{array}$ & $\begin{array}{l}0.00(0) \\
0.92(3) \\
0.37(3)\end{array}$ & $\begin{array}{l}0.22(1) \\
0.96(3) \\
0.55(4)\end{array}$ & $\begin{array}{l}0.00(0) \\
0.69(2) \\
0.32(2)\end{array}$ & $\begin{array}{l}0.00(0) \\
0.84(7) \\
0.43(7)\end{array}$ \\
\hline
\end{tabular}


TABLE IV-Histological classification of breast cancers in women who had ever used oral contraceptives and controls according to age at diagnosis

\begin{tabular}{|c|c|c|c|c|c|c|c|c|}
\hline & \multicolumn{4}{|c|}{35 years } & \multicolumn{4}{|c|}{$>35$ years } \\
\hline & \multicolumn{2}{|c|}{$\begin{array}{c}\text { Oral } \\
\text { contraceptive } \\
\text { users }\end{array}$} & \multicolumn{2}{|c|}{ Controls } & \multicolumn{2}{|c|}{$\begin{array}{c}\text { Oral } \\
\text { contraceptive } \\
\text { users } \\
\end{array}$} & \multicolumn{2}{|c|}{ Controls } \\
\hline & $"$. & No & $\because$ & No & $\%$ & No & $\%$ & No \\
\hline $\begin{array}{l}\text { Intraduct } \\
\text { Invasive: }\end{array}$ & 14 & 3 & 17 & 1 & 9 & 5 & 10 & 5 \\
\hline $\begin{array}{l}\text { Grade I } \\
\text { Grade II } \\
\text { Grade III } \\
\text { No information }\end{array}$ & $\begin{array}{l}14 \\
23 \\
26 \\
23\end{array}$ & $\begin{array}{l}3 \\
5 \\
6 \\
5\end{array}$ & $\begin{array}{l}17 \\
32 \\
17 \\
17\end{array}$ & $\begin{array}{l}1 \\
2 \\
1 \\
1\end{array}$ & $\begin{array}{l}17 \\
26 \\
23 \\
25\end{array}$ & $\begin{array}{r}9 \\
14 \\
12 \\
13\end{array}$ & $\begin{array}{l}19 \\
21 \\
17 \\
33\end{array}$ & $\begin{array}{r}10 \\
11 \\
9 \\
17\end{array}$ \\
\hline Total & 100 & 22 & 100 & 6 & 100 & 53 & 100 & 52 \\
\hline
\end{tabular}

Oral contraceptive users were likely to have had more frequent consultations with their general practitioners than the control subjects, so it was important to determine whether this could have led to a diagnostic bias. In fact, in only $5 \%$ of both users and controls (from table $\mathrm{V}$ ) was the lesion discovered by the doctor as a result of a routine examination (screening). The remainder presented to their doctor complaining of a lump in the breast (symptomatic), or the information on presentation was unavailable $(13 \%$ of users and $12 \%$ of controls).

There were no important differences in the age at the birth of the first child between the women with breast cancer who had used the pill and controls.

The contraceptives used by the controls were recorded only at the time of their recruitment to the study, except for those controls who subsequently used the pill. The subsequent breast-cancer rate in controls who used no contraceptives at recruitment was similar to that of all control subjects.

TABLE $\mathrm{v}-$ Mode of presentation of breast cancer according to age at diagnosis and oral-contraceptive use

\begin{tabular}{|c|c|c|c|c|c|c|c|c|}
\hline & \multicolumn{4}{|c|}{$<35$ years } & \multicolumn{4}{|c|}{$\geqslant 35$ years } \\
\hline & \multicolumn{2}{|c|}{$\begin{array}{c}\text { Oral } \\
\text { contraceptive } \\
\text { users }\end{array}$} & \multicolumn{2}{|c|}{ Controls } & \multicolumn{2}{|c|}{$\begin{array}{c}\text { Oral } \\
\text { contraceptive } \\
\text { users }\end{array}$} & \multicolumn{2}{|c|}{ Controls } \\
\hline & $\%$ & No & $\%$ & No & $\%$ & No & $\%$ & No \\
\hline $\begin{array}{l}\text { Screening } \\
\text { Symptomatic } \\
\text { No information }\end{array}$ & $\begin{array}{r}4 \\
82 \\
14\end{array}$ & $\begin{array}{r}1 \\
18 \\
3\end{array}$ & $\begin{array}{r}0 \\
83 \\
17\end{array}$ & $\begin{array}{l}0 \\
5 \\
1\end{array}$ & $\begin{array}{r}6 \\
81 \\
13\end{array}$ & $\begin{array}{r}3 \\
43 \\
7\end{array}$ & $\begin{array}{r}5 \\
83 \\
12\end{array}$ & $\begin{array}{r}3 \\
43 \\
6\end{array}$ \\
\hline Total & 100 & 22 & 100 & 6 & 100 & 53 & 100 & 52 \\
\hline
\end{tabular}

\section{Discussion}

The predominant bias in this study arose from increased reporting of symptoms by oral-contraceptive users, rather than by biased diagnoses by the doctor. ${ }^{1}$ This biased reporting was important in relation to common, less serious conditions that are often unreported to doctors, and the bias became minimal, or absent, for well-defined serious diseases that would always be brought to medical attention. It is therefore unlikely that biased reporting could have accounted for the excess of young oralcontraceptive users with breast cancer. Women who use oral contraceptives usually attend their doctors more often than nonusers, and a breast lesion that was previously unnoticed might be detected during the course of a routine examination. In fact, this occurred in only one case (in a user) in women under 35 years of age and in only $5 \%$ of both users and controls of all ages. Users of oral contraceptives may be more aware of their breasts than non-users, so that they would be more likely to notice a lump. There is no reason why this should apply only to young users, nor could earlier detection of a lump have resulted in earlier diagnosis by as much as five to 10 years. There was, therefore, no evidence of material biased reporting or diagnosis.

About half the original study population was lost to follow-up. In this study the loss was almost entirely due to death or retirement of participating doctors or removal of subjects to another area. Neither circumstance is likely to be associated with a change of contraceptive practice or with susceptibility to a disease. Nevertheless, we have repeatedly monitored the characteristics of the subjects lost to observation and compared them with those of the original cohorts. As in the past, those that left had a slightly lower parity, a slightly higher social class and were slightly younger than those remaining. Nevertheless, these differences applied similarly to users of oral contraceptives and non-users. Interestingly, the smoking habits of those who left were virtually identical to those of the original cohorts-an important observation, since smoking may be associated with personality factors that have not been measured. The small differences between the cohorts in the major characteristics that have resulted from the loss of subjects may be adequately controlled by standardisation. While there may be other differences of which we are not aware, these seem unlikely to be important, since we cannot postulate any circumstances on the basis of the known epidemiology of breast cancer that could be associated with biased recording of breast cancer as a result of loss of subjects in the special conditions of our study.

Women who use oral contraceptives are a selected population. They are self-selected, since they have chosen the method, and they are medically selected, since doctors normally advise against oral-contraceptive use in women with a poor medical history. If the choice of contraceptive were associated with an altered risk of breast cancer this would have an important effect on the estimation of the risk of breast cancer in users of oral contraceptives. Vessey $e t a l^{6}$ have identified one such potentially confounding factor. In their large, case-control study there was an excess in the control group of women who had never used any contraceptive. This implies that this group of women had a lowered risk of breast cancer. Since they used no contraceptives they were not "at risk" of using the pill and probably should be excluded from the analyses. Our information about contraceptive use other than the pill was collected only at recruitment. Among the controls, and excluding those women who were using no contraceptives because they were pregnant or recently pregnant, those not using contraceptives had a subsequent breast-cancer rate similar to that of other control subjects. This does not refute the observation of Vessey et al, ${ }^{6}$ because we know that $20 \%$ of these initial non-users subsequently used oral contraceptives, and some are likely to have adopted other contraceptive practices. The issue is important, and further evidence is required urgently. If the observation is confirmed, excluding those who do not use contraceptives would lower the estimated risk of breast cancer associated with oral-contraceptive use in both cohort and case-control studies.

Bias is therefore unlikely to have influenced our observations. It is impossible to be certain of this, however, and it is important to seek evidence from within the user group that is independent of any potential bias between users and controls. Our limited information is reassuring. There was no convincing evidence of a relation to oestrogen or progestogen dose or of any effect of duration of oral-contraceptive use. We were unable to investigate properly certain important subgroups of users. We could not estimate whether there was an interaction between age at first birth and pill use because we did not have the information for the study population. Our information about oral-contraceptive use and pregnancy before recruitment was not sufficiently detailed to enable us to identify those parous women who began taking the pill before their first pregnancy, and the proportion of users who were nulliparous at recruitment $(15 \%)$ was too small to be useful. Benign breast disease is an accepted risk factor for the subsequent development of breast cancer. At recruitment 2.3 per 1000 users and 3.6 per 1000 controls had a history of benign breast disease. After recruitment, however, significantly fewer cases of benign breast disease were reported in oral-contraceptive users than in controls, ${ }^{1}$ so users might be expected to have a lower risk of breast cancer than non-users. Nevertheless, the pill probably reduces the risk only in those types of benign breast disease that are least likely to predispose to malignancy. ${ }^{7} \mathrm{Six}$ of the oral-contraceptive users with breast 
cancer and five controls were reported to have had benign breast disease. The breast-cancer rate in women with benign breast disease was approximately 0.7 per 1000 women-years in both users and controls, but the number of malignancies was too small to provide reliable estimates of risks.

Finally, we must interpret our results in the light of evidence from other studies. The relevant reports are both confusing and conflicting. One cohort study ${ }^{8}$ and several case-control studies have shown essentially no association of oral-contraceptive use with breast cancer, ${ }^{9-13}$ but few of the women with cancer were of reproductive age, and the conclusions were not convincing. Brinton et $a l^{14}$ showed several adverse interactions of oral contraceptives with established risk factors for breast cancer, but again the numbers were small and few of the associations were statistically significant.

Three case-control studies merit further consideration. Paffenbarger and his colleagues have been examining data collected in the San Francisco Bay area. Their original study ${ }^{15}$ was based on 452 cases of breast cancer. Although the overall relative risk of breast cancer in those who had ever used oral contraceptives was $1 \cdot 1$, a significantly increased relative risk of 1.9 was found in women who had used the pill for two to four years, but there was no increased risk in women with a shorter or longer period of use. In women with previous benign breast disease oral-contraceptive use for longer than six years resulted in an elevenfold increased risk of breast cancer when compared with the non-users. Further analyses of these data ${ }^{16}$ showed a significant threefold increased risk of breast cancer in women who began taking oral contraceptives before their first childbirth. The study was later extended to include a total of 1423 cases of breast cancer. ${ }^{17}$ The overall relative risk in women who had ever used the pill was then estimated at $1 \cdot 19$ (not significant), but the risk rose to 1.38 after two years of use and remained at that level with longer use. The previously shown increased risk in users with a history of benign breast disease and in those who started taking the pill before their first childbirth was no longer apparent.

None of these adverse effects could be confirmed by Vessey et al. ${ }^{6}$ Their study was based on 707 women with breast cancer with an upper age limit of 50 years. Their findings were convincingly negative for adverse effects of oral contraceptives and, indeed, there was a suspicion of a beneficial effect. Users of oral contraceptives had less advanced tumours at presentation than the non-users, and this was associated with a favourable survival pattern.

A recent paper from Pike et al ${ }^{18}$ described a case-control study of Californian women whose breast cancer was diagnosed under the age of 33 years. They found a statistically significantly increased risk of breast cancer in women who had used oral contraceptives for more than four years before their first fullterm pregnancy (relative risk $2 \cdot 2$ ). There was also a significant adverse interaction between oral-contraceptive use and benign breast disease when both had occurred before the first full-term pregnancy. Certain features of this study lead us to regard the conclusions with caution. Firstly, the investigators were able to interview only 163 out of a total of 245 eligible patients, and this might have resulted in the analysis of a biased sample. Secondly, it is not clear whether they adjusted adequately for any differences between their case and control subjects in the interval between the menarche and the first full-term pregnancy. A long interval is in itself a risk factor for breast cancer, and it may well be associated with prolonged use of oral contraceptives for the voluntary postponement of the first pregnancy.

The Oxford-Family Planning Association cohort study (see accompanying paper, p 2093) showed no evidence of adverse effects of oral contraceptives. There were only 14 cases under the age of 35 years, and the relative risk was 0.61 in this subgroup. Spencer et $a l^{19}$ compared the disease and prognosis in 44 patients with breast cancer who had recently used oral contraceptives with those in the same number of matched nonusers. They found no important differences in the clinical staging, the histology, or the survival between the two groups.
Our finding of an increased risk of breast cancer in young users of oral contraceptives has to be considered in the light of all the available evidence. The excess risk was not statistically significant, and there is no supporting evidence from our own data. The findings of Pike and his colleagues ${ }^{18}$ are consistent with our own, but the data are not entirely comparable. Other studies that have examined specifically the effects of oral-contraceptive use before the first full-term pregnancy have not shown an adverse effect. ${ }^{617}$ Other adverse effects shown in some studies, including the interaction with benign breast disease, are inconsistent and unstable. In all these circumstances, and bearing in mind our reservations about the analyses of the Pike study, we believe it is proper to regard our results as due to confounding or an effect of chance.

Because the subject is so important, it may be helpful to consider some possible explanations for the unusual number of conflicting and unstable observations. Investigating a possible association between oral-contraceptive use and breast cancer is especially difficult. There are substantial geographical differences in the incidence of breast cancer, ${ }^{20}$ so that the results of studies in one country would not necessarily be applicable in another. Also the effect of a weak carcinogen might not be shown until exposure had been continued for 10 years or more. Only $6 \%$ of the experience in our study applied to women with more than 10 years of pill use. In Paffenbarger's study, ${ }^{17}$ only $5 \%$ of subjects had more than six years' use. Similarly, only $3 \%$ of the patients studied by Vessey $e t a l^{6}$ had used the pill for more than eight years. Duration of exposure may not, however, be the most critical factor. One of the most important determinants of the risk of breast cancer in women is the age at which the first child is born. ${ }^{4} \mathrm{~A}$ woman who has her first child before the age of 18 years has only $40 \%$ of the risk of breast cancer of a nulliparous woman, but if the first birth is delayed until after the age of 35 the risk is $20 \%$ greater than for a nulliparous woman. These changes in risk are permanent.

The epidemiological evidence strongly suggests that the initiation of breast cancer in women occurs predominantly in the 10-15 years after the menarche. ${ }^{21}$ This implies a latent period of at least 20-30 years. If oral contraceptives have any effect on breast cancer-adverse or beneficial-a similar latent period would probably operate. Oral contraceptives were introduced into the USA in 1959 and into Britain the following year. It is therefore possible that no data yet exist which would be capable of reliably showing an effect. Moreover, the timing of the first use of oral contraceptives in relation to tumour initiation may be crucial, so that some groups of women could be affected differently from others. It is, therefore, essential that we continue to monitor large numbers of women for many more years, in different places.

We thank Professor A C Thackray, emeritus professor of morbid histology, University of London, for classification of the histology of breast tumours, Dr W H W Inman and his staff at the Committee on Safety of Medicines for arranging to collect the biopsy material, and the 1400 general practitioners who contributed data for this survey. The study is supported by a major grant from the Medical Research Council. The costs of the pilot trials and current supplementary expenditure have been met by the Scientific Foundation Board of the Royal College of General Practitioners. The Board thanks Organon Laboratories Ltd, Ortho Pharmaceutical Corporation, Schering Chemicals Ltd, G D Searle and Co Ltd, Syntex Pharmaceuticals Ltd, and John Wyeth and Brother Ltd for financial support.

\section{References}

${ }^{1}$ Royal College of General Practitioners. Oral contraceptives and health. London: Pitman Medical, 1974.

${ }^{2}$ Miettinen OS. Estimability and estimation in case-referrent studies. $\mathrm{Am} \mathcal{F}$ Epidemiol 1976;103:226-35.

${ }^{3}$ Scarff RW, Torloni H. Histological typing of breast tumours. Geneva: World Health Organisation, 1968. (International histological classification of tumours, No 2.)

4 MacMahon B, Cole P, Lin TM, et al. Age at first birth and breast cancer risk. Bull WHO 1970;43:209-21. 
${ }^{5}$ Peto R, Pike MC, Armitage P, et al. Design and analysis of randomized clinical trials requiring prolonged observation of each patient. II. Analysis and examples. Br $\mathcal{F}$ Cancer $1977 ; 35: 1-39$.

${ }^{6}$ Vessey MP, Doll R, Jones K, McPherson K, Yeates D. An epidemiological study of oral contraceptives and breast cancer. Br Med f 1979;i:1757-60.

${ }^{7}$ Livolsi VA, Stadel BV, Kelsey JL, Holford TR, White C. Fibrocystic breast disease in oral-contraceptive users. N Englf Med 1978 ;299:381-5.

${ }^{8}$ Ory H, Cole P, MacMahon B, Hoover R. Oral contraceptives and reduced risk of benign breast disease. N Engl f Med 1976;294:419-22.

- Boston Collaborative Drug Surveillance Program. Oral contraceptives and venous thromboembolic disease, surgically confirmed gall-bladder disease, and breast tumours. Lancet 1973; i :1399-404.

10 Arthes FG, Sartwell PE, Lewison EF. The Pill, estrogens, and the breast. Epidemiological aspects. Cancer $1971 ; 28: 1391-4$.

${ }^{11}$ Henderson BE, Powell D, Rasario I, et al. An epidemiologic study of breast cancer. 7 Natl Cancer Inst 1974;53:609-14.

${ }^{12}$ Kelsey JL, Holford TR, White C, Mayer E, Kilty SE, Acheson RM. Oral contraceptives and breast disease. Am $\mathcal{F}$ Epidemiol 1978;107:236-44.

13 Ravnihar B, Seigel DG, Lindtner J. An epidemiologic study of breast cancer and benign breast neoplasias in relation to the oral contraceptive and oestrogen use. Eur $\mathcal{F}$ Cancer 1979;15:395-405.

14 Brinton LA, Williams RR, Hoover RN, Stegens NL, Feinleib M, Fraumeni
JF Jr. Breast cancer risk factors among screening program participants. $\mathcal{f}$ Natl Cancer Inst 1979;62:37-44.

15 Fasal E, Paffenbarger RS Jr. Oral contraceptives as related to cancer and benign lesions of the breast. $\mathcal{F ~ N a t l ~ C a n c e r ~ I n s t ~} 1975$;55:767-73.

${ }^{16}$ Paffenbarger RS Jr, Fasal E, Simmons ME, Kampert JB. Cancer risk as related to use of oral contraceptives during fertile years. Cancer 1977; 39: 1887-91.

${ }_{17}$ Paffenbarger RS Jr, Kampert JB, Chang H-G. Oral contraceptives and breast cancer risk. In: The regulation of fertility evaluation and perspectives. Paris: Institut National de la Santé et de la Recherche Medicale, 1979:93-114.

18 Pike MC, Henderson BE, Casagrande JT, Rosario I, Gray GE. Oral contraceptive use and early abortion as risk factors for breast cancer in young women. $B r \mathcal{F}$ Cancer $1981 ; 43: 72-6$.

19 Spencer JD, Millis RR, Hayward JL. Contraceptive steroids and breast cancer. Br Med f 1978; :1024-6.

${ }^{20}$ Doll $\mathrm{R}$. The epidemiology of cancers of the breast and reproductive system. Scott Med f 1975;20:305-15.

${ }^{21}$ MacMahon B, Cole P, Brown J. Etiology of human breast cancer: A review. F Natl Cancer Inst 1973;50:21-42.

\title{
Breast cancer and oral contraceptives: findings in Oxford-Family Planning Association contraceptive study
}

\author{
M P VESSEY, KLIM MCPHERSON, RICHARD DOLL
}

\begin{abstract}
Among the 17032 women taking part in the OxfordFamily Planning Association contraceptive study, 72 were first diagnosed as having breast cancer between the date they were admitted to the study and 1 September 1980. The relative risk of developing the disease in women who had used oral contraceptives in comparison with those who had never used them was estimated to be 0.96 (95\% confidence limits 0.59 to 1.63$)$. Among women aged under 35 years, the corresponding relative risk (based on only 14 women with breast cancer) was estimated to be 0.61 .

No relation was apparent between the risk of developing breast cancer and duration of oral-contraceptive use or interval since first oral-contraceptive use in any age group. The data in this study are thus reassuring; but observations based on women with long-term use of oral contraceptives, especially those starting to use the preparations at an early age, are few.
\end{abstract}

\section{Introduction}

Data about breast cancer collected during the course of the Royal College of General Practitioners (RCGP) Oral Contraception Study are described in the preceding paper (p 2089). This report is concerned with similar information obtained in the second large British cohort study of the effects of the pill, the Oxford-Family Planning Association Contraceptive Study.

\footnotetext{
University Department of Community Medicine and General Practice, Oxford OX1 3QN

$M$ P VESSEY, MD, FRCPED, professor

KLIM MCPHERSON, MA, PHD, university lecturer

Imperial Cancer Research Fund Cancer Epidemiology and Clinical Trials Unit, Oxford OX1 3QG

SIR RICHARD DOLL, DM, FRS, honorary director
}

\section{Methods}

A detailed account of the methods used in the Oxford-Family Planning Association study has been given elsewhere. ${ }^{1}$ In brief, 17032 women were recruited at 17 large family planning clinics in England and Scotland during 1968-74. At the time of recruitment, each of these women had to be: (a) aged 25-39 years, (b) married, $(c)$ a white British subject, $(d)$ willing to participate, and $(e)$ either a current user of oral contraceptives with at least five months' use or a current user of a diaphragm or an intrauterine device with at least five months' use and without prior exposure to the pill. During follow-up each woman is questioned at return visits to the clinic by a doctor or nurse and certain items of information are noted on a special form, including details of pregnancies and their outcome, changes in contraceptive practice, and reasons for referral to hospital as an outpatient or inpatient. Women who stop attending the clinic are sent a postal version of the questionnaire and, if this is not returned, are interviewed on the telephone or at a home visit. The work in each clinic is co-ordinated by a part-time research assistant, and follow-up has been maintained with an annual loss rate for "relevant" reasons (withdrawal of co-operation or loss of contact) of only about $0.3 \%$.

The results presented here concern 72 women with histologically proved cancer of the breast first diagnosed during follow-up before 1 September 1980. The analysis of the data was based on the computation of woman-years of observation in the various groups compared. Breast-cancer incidence rates were standardised by the indirect method as described by Vessey et al. ${ }^{1}$ Use of the pill before entry to the study was taken into account during the computation of breastcancer incidence rates in relation to total duration of oral contraceptive use and to interval since oral contraceptives were first used.

\section{Results}

Preliminary analysis showed the general pattern of occurrence of breast cancer in the Oxford-Family Planning Association study to be in accordance with the known epidemiology of the disease. ${ }^{2}$ Thus the incidence rate per 1000 woman-years of observation rose from $0 \cdot 22$ in those aged $25-29$ years to 1.05 in those aged 40 years or more, while the age-standardised incidence rates rose from 0.19 in those first giving birth at 20 years or less to 0.52 in those first giving birth at 26 years or more, from 0.43 in those with no history of benign disease of 